\section{Amiodarone and thyroid autoimmunity in the United Kingdom}

\author{
A P Weetman, S K Bhandal, J M Burrin, \\ K Robinson, W McKenna
}

Departments of Medicine and Cardiovascular Disease, Royal

Postgraduate Medical School, and Pharmacy Department,

Hammersmith Hospital, London W12 0HS

A P Weetman, MD, Wellcome Trust senior research fellow in clinical science, department of medicine

S K Bhandal, Msc, pharmacist

J M Burrin, PHD, top grade biochemist, department of medicine

K Robinson, MRCP, research fellow, department of cardiovascular disease W McKenna, MD, senior lecturer, department of cardiovascular disease

Correspondence to: Dr A P Weetman, Department of Medicine, Level 5 ,

Addenbrooke's Hospital Cambridge CB2 2QQ patients.

\section{Patients, methods, and results} assay (IQ Bio, Cambridge).
Amiodarone has a high iodine content, which affects the biochemistry of the thyroid. ${ }^{1}$ Autoimmunity is a second possible mechanism for thyroid disease induced by drugs as intake of iodine modulates thyroid autoreactivity. ${ }^{2}$ In particular, six out of 11 Portuguese patients developed microsomal antibodies 30 days after taking amiodarone. ${ }^{3}$ As there is sufficient iodine in the United Kingdom, unlike in Portugal, we assessed whether amiodarone has similar effects in British

Twenty patients (seven women), mean age 56 (range 27-90), were followed up prospectively from the start of taking amiodarone and a further 42 patients ( 15 women), mean age 51 (range 22-90), were reviewed retrospectively. Titres of thyroglobulin and microsomal antibodies were measured by enzyme linked immunosorbent assay (ELISA) ${ }^{4}$ thyroid stimulating antibodies by estimating production of cyclic adenosine monophosphate by the rat thryoid cell line FRTL $_{5}$, and thyroid stimulating hormone concentration by an enzyme amplified immunometric

In the group studied prospectively half the patients had thyroid antibodies before treatment; in another patient these appeared after 19 months. This high prevalence of antibodies may reflect the patients' age and the sensitivity of the assay. In three patients with antibodies thyroid stimulating hormone concentration was also raised but no consistent change occurred after treatment with amiodarone. Only one patient (case 7) became clinically hypothyroid and antibodies rose in parallel with thyroid stimulating hormone concentration (figure). By contrast, the figure shows that in one patient (case 2) thyroid stimulating hormone concentrations rose when antibody titres were falling. Two patients had transient hyperthyroidism; in one (case 8 ) this was associated with a rise in titres of microsomal antibodies, but neither had thyroid stimulating antibodies.

In the group studied retrospectively, $13(31 \%)$ patients had antibodies at some stage of follow up; this was transient in six, occurring at 11-83 months after they started to take amiodarone. Thyroid stimulating hormone concentration was raised in four patients with antibodies; this was subclinical in three but the other became clinically hypothyroid 62 months after starting to take amiodarone and coincidently developed autoantibodies. Transient hyperthyroidism (without thyroid stimulating antibodies) occurred in two patients; their return to normal was associated in both with a rise in autoantibody titres.

\section{Comment}

Our results do not confirm those showing a high incidence of thyroid autoantibodies after taking amiodarone $^{3}$ and indicate that hyperthyroidism induced by amiodarone is not due to thyroid stimulating antibodies. The time from taking amiodarone to the appearance of autoantibodies in a few patients makes this unlikely to be a direct effect of the drug. The results do, however, suggest that amiodarone can modulate pre-existing thyroid autoantibody titres as noticeable fluctuations were seen within months after patients started to take the drug and we have not seen similar changes in eight untreated patients with antibodies. The effects of amiodarone on thyroid stimulating hormone concentrations may reflect both a biochemical (case 2) and an immunological action (cases 7 and 8), but, clearly, the presence of thyroid autoantibodies before treatment is not strongly associated with subsequent hypothyroidism in the United Kingdom.

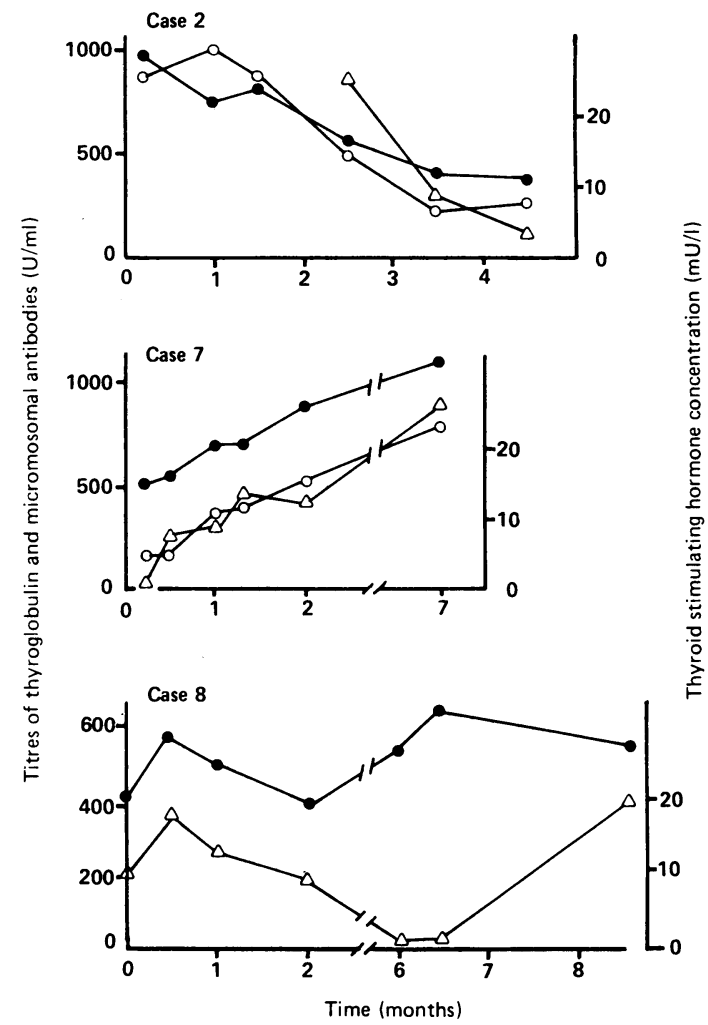

Changes in titres of thyroglobulin $(\mathrm{O}-\mathrm{O})$ and microsomal ( antibodies and thyroid stimulating hormone concentration $(\triangle-\triangle)$ in three patients treated with amiodarone. One patient (case 8) was negative for thyroglobulin antibodies throughout

The difference in response to amiodarone among patients and countries may reflect immunogenetic predisposition and dietary intake of iodine. Amiodarone may cause autoantigen release, ${ }^{5}$ increasing or decreasing the autoimmune response according to the amount released; in our patients continuing thyroid autoimmunity was required for this to occur. In conclusion, amiodarone does not initiate thyroid autoimmunity in the United Kingdom, although in some patients pre-existing disease may be exacerbated, and screening for autoantibodies before treatment has little value in predicting subsequent thyroid dysfunction.

This work was supported by the Wellcome Trust and formed part of an MSc (clinical pharmacy) course for SKB. We thank Dr A Goolden for suggesting this project, and Ms C Woods for technical help.

Weirsinga WM, Trip MD. Amiodarone and thyroid hormone metabolism [review article]. Postgrad Med 7 1986;62:909-14.

2 McGregor AM, Weetman AP, Ratanachaiyavong S, Owen GM, Ibbertson HK, Hall R. Iodine: an influence on the development of autoimmune thyroid disease? In: Hall R, Kobberling J, eds. Thyroid disorders associated with iodine deficiency and excess. New York: Raven Press, 1985:209-16. (Serono symposium No 22 .

3 Monteiro E, Gatrao-Teles A, Santos ML, et al. Antithyroid antibodies as an early marker for thyroid disease induced by amiodarone. $\mathrm{Br}$ Med $\mathcal{f}$ 1986;292:227-8.

4 Weetman AP, Rennie DP, Hassman R, Hall R, McGregor AM. Enzyme-linked immunoassay of monoclonal and serum microsomal autoantibodies. Clin Chim Acta 1984;138:237-44.

5 Smyrk TC, Goellner JR, Brennan MD, Carney JA. Pathology of the thyroid in amiodarone-associated thyrotoxicosis. Am $\mathcal{F}$ Surg Pathol 1987;11:197-204.

(Accepted 28 March 1988) 